\title{
Characterization of sol-gel coatings deposited on a mechanically treated stainless steel by using a simple non-destructive electrical method
}

\author{
Víctor ENCINAS-SÁNCHEZ, Antonio MACÍAS-GARCÍA, ${ }^{* \dagger}$ \\ Ma Ángeles DÍAZ-DÍEZ* and Antonio DÍAZ-PARRALEJo* \\ Department of Materials Science, Faculty of Chemical Sciences. University of Complutense, Madrid, 28040 Madrid, Spain \\ *Department of Mechanical, Energetic \& Materials Engineering, School of Industrial Engineering, University of Extremadura, \\ Avda. de Elvas, s/n, 06006 Badajoz, Spain
}

Coating solution of yttria-doped zirconia was prepared by using the sol-gel method and deposited on AISI 304 stainless steel substrates using dip-coating technique. The influence of the mechanical modification of stainless steel substrates and withdrawal rate on the coating quality has been studied. Herein, a novel method based on measuring the electrical capacitance of such coatings is developed in order to assess the coating quality. The method was performed on sanded and polished samples coated at various withdrawal rates, obtaining the greater thickness uniformity for the coatings deposited on polished specimens coated at a withdrawal rate of $25 \mathrm{~mm} \cdot \mathrm{min}^{-1}$. The results obtained by the proposed method are well in agreement with those found by both optical and electron microscopies. Therefore, such a method seems to be of great interest because of its simplicity and low cost as compared to other well-established techniques, and its results may be a great support for them.

(2016 The Ceramic Society of Japan. All rights reserved.

Key-words : Coating, Sol-gel method, Yttria-doped zirconia, Dip-coating, Characterization

[Received April 17, 2015; Accepted June 28, 2015]

\section{Introduction}

Despite the economic crisis, the still high steel consumption reveals the importance of this material in the engineering field. ${ }^{1)}$ Some kinds of steel are subjected to severe conditions (i.e. high temperatures, oxidizing/reducing atmospheres, and so on $)^{2)}$ which may be lead to a significant loss of their pristine properties. In this connection, a number of methods to reduce or even avoid degradation processes in steels such as corrosion and loss of properties have been reported. ${ }^{3)-5)}$ Among them, surface coating is one of the most widely used. ${ }^{6)-8)}$

Surface protection of steel by using ceramics materials has been long considered as a solution, both from technical and economic point of view, due to their excellent properties, such as chemical inertness, wear resistance, etc. Indeed, the coating of stainless steels with zirconia has been reported to improve their mechanical properties, oxidation resistance, etc. ${ }^{9-12)}$ Moreover, zirconia is stabilized by the addition of oxides which act as dopants, being yttria and calcium oxides the most selected ones. The addition of yttria seems to stabilize the tetragonal and/or cubic phases of zirconia at room temperature, ${ }^{9), 13)-15)}$ thus avoiding the tetragonal-monoclinic transformation which is accompanied with a volume increase. Such increase may lead to a fracture of the material.

Sol-gel method allows obtaining thin oxide films. ${ }^{16)-19)}$ These films can be deposited on the substrate by several techniques, including "spin-coating", "spray-coating", "dip-coating", and "electrophoresis". 20)-24) The immersion method known as "dipcoating" has many advantages such as the possibility of coating

† Corresponding author: A. Macías-García; E-mail: amacgar@ unex.es large surfaces, the simplicity of the equipment, and a low cost. ${ }^{25)}$ As a consequence, dip coating was selected as the coating method in the present work. In the dip coating method, the substrate is first introduced in a vessel containing the sol-gel solution and, then, the material is extracted at a previously fixed and constant speed. After that, a liquid film of an uniform thickness is adhered on the substrate surface. There are many papers in literature dealing with the coating of steel by the sol-gel method $^{26)-28)}$ and using zirconia as coating material. ${ }^{29)-31)}$

Electrical measurements have been carried out by some other authors for studying the quality of numerous types of coatings. ${ }^{32), 33)}$ In this aspect, to the best of our knowledge, no author has analysed uniformity of coating's thickness by using this type of measurements, although some of them have used other techniques with the same objective. ${ }^{34), 35)}$

This paper is aimed at investigating the influence of the mechanical modification of the substrate surface (i.e. surface roughness) and the withdrawal rate on the preparation of uniform zirconia coatings and their electrical properties. The proposed method allows determining both the homogeneity and uniformity of the coatings in a cheaper and simpler way as compared to other well-established techniques.

\section{Experimental procedure}

\subsection{Material}

AISI 304 stainless steel, austenitic steel characterized by a low carbon content, was used as substrate. Test pieces of $20 \times 50 \times$ $2 \mathrm{~mm}$ with a composition (in weight percent) of $0.08 \% \mathrm{C}, 2.0 \%$ $\mathrm{Mn}, 18.7 \% \mathrm{Cr}, 11.0 \% \mathrm{Ni}, 0.045 \% \mathrm{P}, 0.03 \% \mathrm{~S}$, and balanced $\mathrm{Fe}$, were manufactured. 
Table 1. Sequence of the mechanical surface treatments applied to the samples

\begin{tabular}{|c|c|c|c|c|c|c|}
\hline & First sandpaper & Second sandpaper & Third sandpaper & 1st polishing cloth & 2nd polishing cloth & 3rd polishing cloth \\
\hline Polished samples & $\mathrm{P} 240$ & $\mathrm{P} 600$ & P800 & $9 \mu \mathrm{m}$ & $6 \mu \mathrm{m}$ & $3 \mu \mathrm{m}$ \\
\hline Type A samples & $\mathrm{P} 240$ & & & - & - & - \\
\hline Type B samples & $\mathrm{P} 240$ & P600 & - & - & - & - \\
\hline Type C samples & P240 & P600 & P800 & - & - & - \\
\hline Type D samples & P800 & - & - & - & 一 & 一 \\
\hline
\end{tabular}

\subsubsection{Surface preparation and characterization of the material}

A rough surface can provide various types of coating distributions depending on the initial degree of surface roughness. ${ }^{36}$ ) On this basis, in this study the test pieces were mechanically modified by sanding and polishing following the procedure summarized in Table 1. Treatment on each surface was carried out for $5 \mathrm{~min}$ at a force of $30 \mathrm{~N}$. The surface modification was followed by ultrasonic cleaning with alcohol and de-ionized water.

The uniformity level of the samples was characterized by a portable roughness tester model Dataview TR-200, determining the Ra parameter (average surface roughness), which is one of the most representative for the study of the modification of the specimen surface. ${ }^{37), 38)}$ The measurements were carried out with a $1-\mathrm{mN}$ contact force and a cut-off length of $0.25 \mathrm{~mm}$, and it were performed on various points for determining an average value.

\subsection{Substrate coating}

\subsubsection{Preparation and characterization of the sol- gel solution}

Coating solution of yttria-doped zirconia was prepared by mixing two previously prepared solutions. ${ }^{39)}$ The first solution contained zirconium N-propoxide/1-propanol $/ \mathrm{H}_{2} \mathrm{O} / \mathrm{HNO}_{3}$ with a molar ratio $1 / 15 / 6 / 1$, while the second one was formed by yttrium acetate/2-propanol $/ \mathrm{H}_{2} \mathrm{O} / \mathrm{HNO}_{3}$ with a molar ratio $1 / 15$ / $6 / 1$, at a $\mathrm{pH} 0.5$. The resulting solution was characterized by measuring its density and viscosity at room temperature, using a Gay-Lussac pycnometer for liquids of $10 \mathrm{ml}$ and an Ostwald modified type capillary viscometer, respectively. A digital thermometer with an accuracy of $0.3^{\circ} \mathrm{C}$ was used for measuring the temperature both of the solutions and distilled water. Viscosity was obtained from the passing time measurement using the following equation:

$$
\eta_{\mathrm{sol}}=\frac{t_{\mathrm{sol}} \cdot \rho_{\mathrm{sol}} \cdot \eta_{\mathrm{H}_{2} \mathrm{O}}}{t_{\mathrm{H}_{2} \mathrm{O}} \cdot \rho_{\mathrm{H}_{2} \mathrm{O}}}
$$

where $\eta_{\text {sol }}, t_{\text {sol }}$, and $\rho_{\text {sol }}$ are the viscosity (cP), the passing time (s) and de density of the solution $\left(\mathrm{g} \cdot \mathrm{cm}^{-3}\right)$, respectively, $t_{\mathrm{H}_{2} \mathrm{O}}$ and $\rho_{\mathrm{H}_{2} \mathrm{O}}$ are the passing time (s) and the density of $\mathrm{H}_{2} \mathrm{O}$ $\left(\mathrm{g} \cdot \mathrm{cm}^{-3}\right)$, and $\eta_{\mathrm{H}_{2} \mathrm{O}}$ is the viscosity $(\mathrm{cP})$ of $\mathrm{H}_{2} \mathrm{O}$ measured at room temperature. ${ }^{40)}$

\subsubsection{Coating and sintering}

The coating was performed by dip-coating at $25^{\circ} \mathrm{C}$. In such a technique the substrate is first immersed in a vessel containing the sol-gel solution and, subsequently, it is extracted under stationary conditions and at a constant speed, thus resulting in a liquid thin film adhered to the substrate surface. Once the deposition process was concluded, the coated samples were heattreated in a Nabertherm ${ }^{\circledR}$ oven at a constant heating and cooling speed of $3^{\circ} \mathrm{C} \cdot \mathrm{min}^{-1}$ in two phases, in order to densify the coating and remove most of the organic load. The first consisted of a drying at $100^{\circ} \mathrm{C}$ for $60 \mathrm{~min}$. and the second was a sintering phase

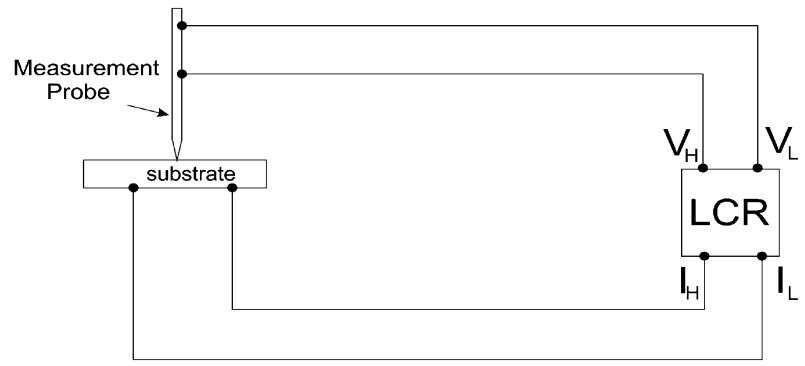

Fig. 1. Equipment used for the electrical measurements.

at a temperature of $500^{\circ} \mathrm{C}$ for $120 \mathrm{~min}$.

\subsubsection{Coating characterization}

Numerous papers consist of studying the quality of thin films using reflected light optical microscopy and scanning electron microscopy. ${ }^{41), 42)}$ A Nikon ${ }^{\circledR}$ reflected light optical microscope (Epiphot 300) was used in order to assess the structural quality and the check the presence of fissures and cracks in the coatings. The microstructural evolution of the coating surface was followed by scanning electron microscopy (SEM) using a Quanta ${ }^{\circledR}$ 3D FEG (FEI) microscope. This technique also allows determining the coating thickness.

Various authors have studied the degree of thickness uniformity and homogeneity of thin films using numerous methods. ${ }^{43), 44)}$ In this way, in this paper an electrical characterization is carried out in order to analyse the quality of thin films. The electrical characterization was accomplished by a simple method, which provides an estimation of the uniformity of the coating's thickness. The proposed method consists of measuring the response of the impedance of the coated test pieces by using a LCR Precision 1920 equipment with a measurement probe $(1 \mathrm{~mm}$ of diameter) and applying an $\mathrm{AC}$ current at a frequency range of $10^{2}-10^{6} \mathrm{~Hz}$. The measurement method was the four point probe, a simple method which consists of passing a current through two outer probes and measuring the voltage through the inner probes, permitting the measurement of the resistivity and capacitance of the coated substrates under study ${ }^{45)}$ A diagram of the equipment used to carry out the proposed electrical method is shown in Fig. 1. Thus, from the measurements the electrical capacitance is determined, which permits the study of the coating's uniformity. This was estimated by applying the following expression [Eq. (2.1)]:

$$
C=\varepsilon_{0} \cdot \varepsilon_{\mathrm{r}} \cdot \frac{S}{e}
$$

where $C$ is the electrical capacitance, $\varepsilon_{0}$ is the dielectric constant of vacuum $\left(8,85 \cdot 10^{-14} \mathrm{~F} \cdot \mathrm{cm}^{-1}\right), \varepsilon_{\mathrm{r}}$ is the relative dielectric constant, $S$ denotes the surface area of the graphite electrode, and $e$ is the coating thickness. Attempting to Eq. (2.2), it is shown that the capacitance of the coating is inversely proportional to its thickness, which permits the estimation of the coating's uni- 
formity. Thus, by recording the electrical capacitance at various equidistant points (16 points) perfectly distributed over the coated area of the substrate, and plotting these capacitance values ( $Z$ axis) versus the coordinates of the points studied (axes $X$ and $Y$ ), it is possible to obtain a map of the coated surface, where a colour scale, which represents the intervals of the measured capacitance values, is used, i.e. it indirectly represents the coating thickness distribution on the substrate surface from a qualitative point of view. Therefore, uniformity in the thickness of the deposited coatings can be studied easily by observing the surface maps obtained by this simple method. Furthermore, to the best of our knowledge, this is the first time that electrical measurements are used for the determination of coatings' uniformity and, given its simplicity and low cost, it would be of great interest to support other well-established techniques, such as ToF-SIMS or XPS. ${ }^{45)-47)}$

\section{Results and discussion}

\subsection{Material characterization}

In this work AISI 304 stainless steel was selected, mainly due to its widespread use in industry because of its excellent properties. Numerous authors have studied ceramic coatings using stainless steel test pieces as substrate. ${ }^{48)-50)}$ The substrates were mechanically modified by sanding and polishing, with the object of studying its influence on the quality of the coatings subsequently deposited on them.

The Ra parameter measured for the mechanically modified samples before being coated are depicted in Fig. 2. As expected, $\mathrm{Ra}$ decreases with increasing severity of the applied mechanical treatment varying between $0.153 \mu \mathrm{m}$ (original samples) and $0.004 \mu \mathrm{m}$ (polished samples). A similar Ra value is measured in the Type B, C, and D samples, observing a quite clear drop in the value of this parameter for the polished sample. Attending to the polished sample, the obtained $\mathrm{Ra}$ parameter presents a lower value in comparison with other studies where polished substrates with $\mathrm{R}_{\mathrm{a}}$ values of $0.050 \mu \mathrm{m}$ are used. ${ }^{51), 52)}$

The evolution of the surface roughness also becomes apparent by optical microscopy, as can be seen from the micrographs for the original and the polished substrates (see Fig. 3). The micrograph (a), exhibiting higher Ra values, reveals a homogeneous surface roughness, while the lower Ra values corresponding to the sample in micrograph (b) are indicative of a uniform surface termination.

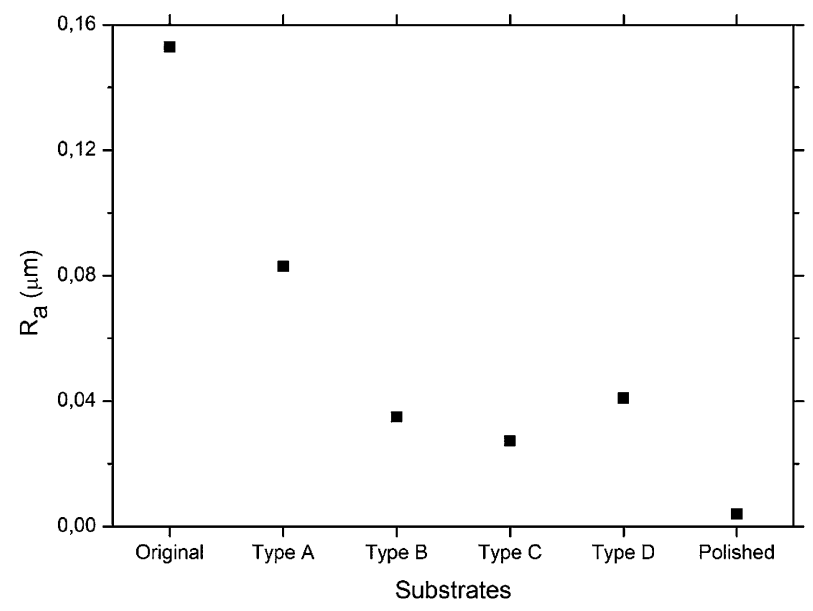

Fig. 2. Comparison of the Ra parameter values obtained for the different specimens.

\subsection{Substrate coating}

\subsubsection{Sol-gel solution characterization}

The yttria-doped zirconia sol-gel solution was obtained by the experimental procedure described above. The sol prepared, as expected, was stable, clear and transparent. Table 2 shows the passing time values of the coating solution measured at numerous temperatures with the object of studying the solution viscosity at various temperature conditions [Eq. (2.1)]. Thus, Fig. 4 shows the viscosity values measured at the selected range of temperatures $\left(10-30^{\circ} \mathrm{C}\right)$. As Fig. 4 shows, viscosity decreases from 1.3
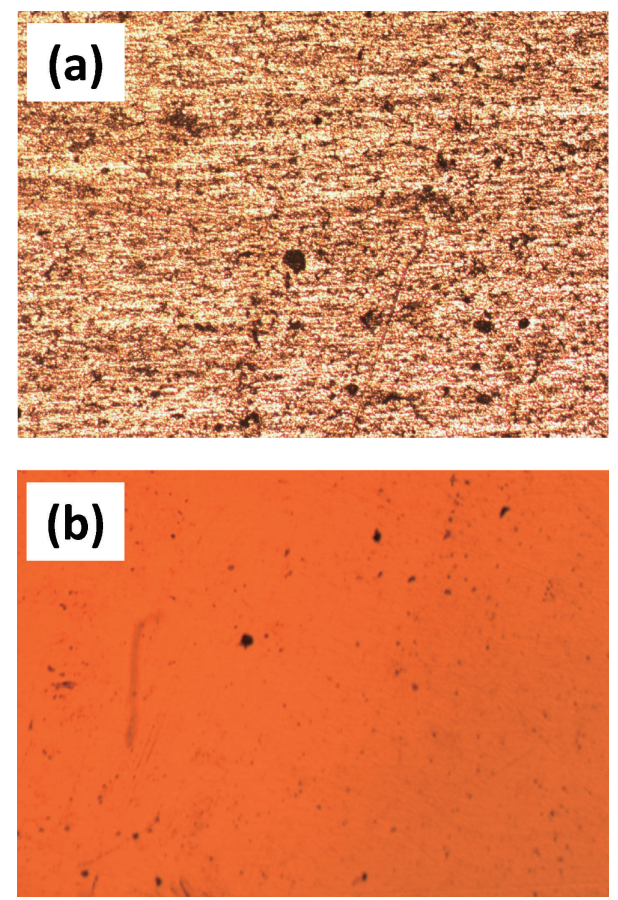

Fig. 3. Optical micrographs of the substrates: (a) original; and (b) polished.

Table 2. Solution passing time at various temperatures

\begin{tabular}{cccccccc}
\hline Temperature $\left({ }^{\circ} \mathrm{C}\right)$ & 10 & 15 & 20 & 22 & 23 & 25 & 30 \\
Passing time $(\mathrm{s})$ & 78 & 73 & 68 & 66 & 65 & 63 & 58 \\
\hline
\end{tabular}

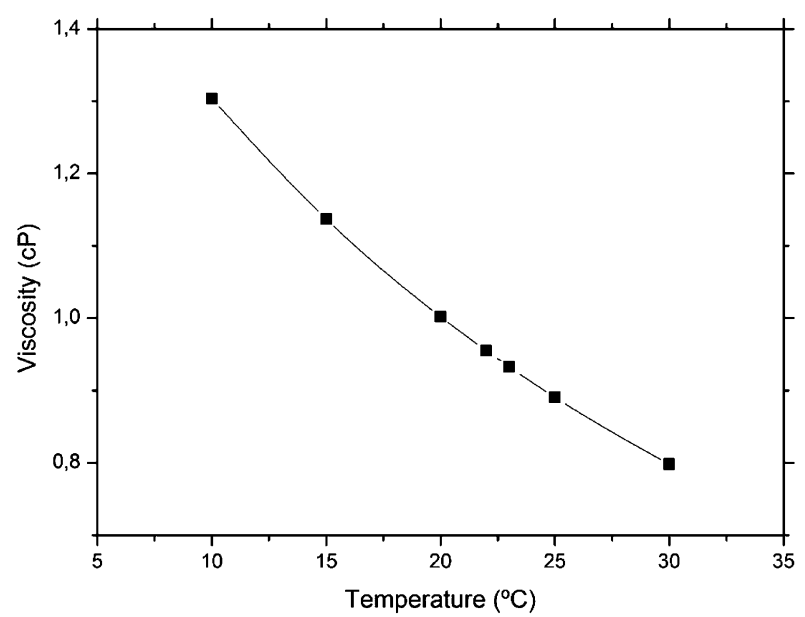

Fig. 4. Variation of the viscosity of the sol-gel solution with the temperature. 


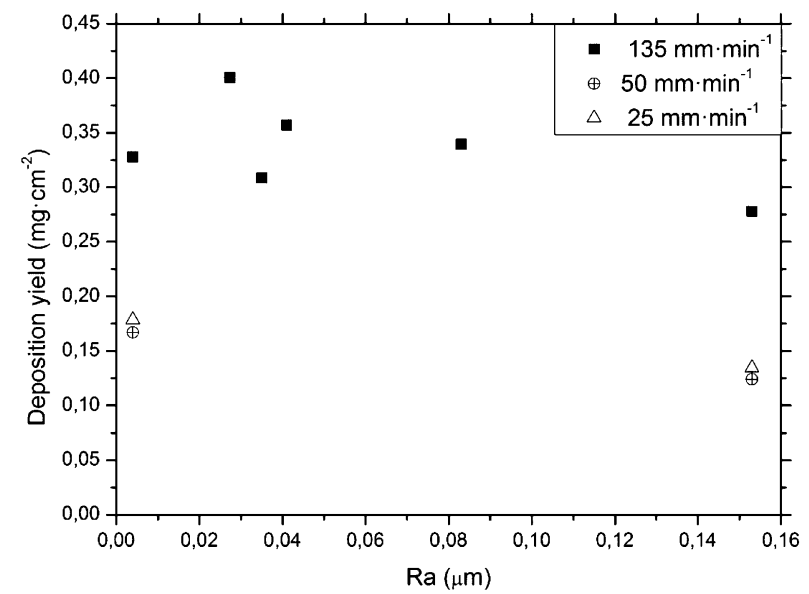

Fig. 5. Deposition yield according to the Ra parameter and withdrawal rate.

to $0.8 \mathrm{cP}$ with the temperature in a quasi-linear way. Thus, observing the results, the temperature of $25^{\circ} \mathrm{C}$ was selected as working temperature, since at this temperature the solution viscosity value $(0.89 \mathrm{cP})$ leads to a good behaviour of the solution as thin film and it enables the correct deposition on substrates. Furthermore, the selected temperature is the normal workplace temperature.

The final density of the yttria-doped zirconia sol-gel solution was $0.966 \mathrm{~g} \cdot \mathrm{cm}^{-3}$, the $\mathrm{pH}$ was kept around 0.5 , and the final molar ratio precursor/alcohol $/ \mathrm{H}_{2} \mathrm{O} / \mathrm{HNO}_{3}$ was $1 / 15 / 6 / 1$, containing $3 \mathrm{~mol} \%$ yttria.

Thus, in this work, the described sol-gel solution was used to coat test pieces of stainless steel, whose surface was previously modified, by the dip-coating technique.

\subsubsection{Coating characterization}

The yield of the ceramic material deposition after sintering versus the roughness of the samples for different withdrawal rates is shown in Fig. 5. It is seen that the higher the roughness, the larger the contact surface for the sol-gel solution and, as a consequence, more $\mathrm{ROH}$ and $\mathrm{H}_{2} \mathrm{O}$ may be released during the sintering. A withdrawal speed reduction during the coating process results in a decrease in the amount of ceramic deposited, reaching a limit coating thickness at a withdrawal speed of 25 $\mathrm{mm} \cdot \mathrm{min}^{-1}$. This fact may lead to more uniform and homogeneous coatings.

The textural characterization of the coatings was accomplished by optical microscopy. Micrographs for selected samples are gathered in Fig. 6, which clearly reveal the coating improvement with the severity of the mechanical treatment of the substrates and, thereby, with lowering Ra. Furthermore, it is worth mentioning that the surface termination is more uniform and homogeneous when decreasing Ra.

It is well known that the main defect appearing in a ceramic coating deposited by sol-gel is the cracking due to the emergence of stresses. An estimation of the stress ${ }^{52)}$ is given by the Eq. (3.1).

$$
\sigma=\left[\frac{E}{1-v}\right] \cdot\left[\frac{f_{\mathrm{s}}-f_{\mathrm{r}}}{3}\right]
$$

where $E$ is the Young's modulus of the coating, $v$ is its Poisson's coefficient, $f_{\mathrm{s}}$ denotes the volumetric fraction of solvent at the solidification point, and $f_{\mathrm{r}}$ is the volumetric fraction of residual solvent in the dried coating. Eq. (3.1) shows that the solvent content, at the solidification point, should be minimized in order
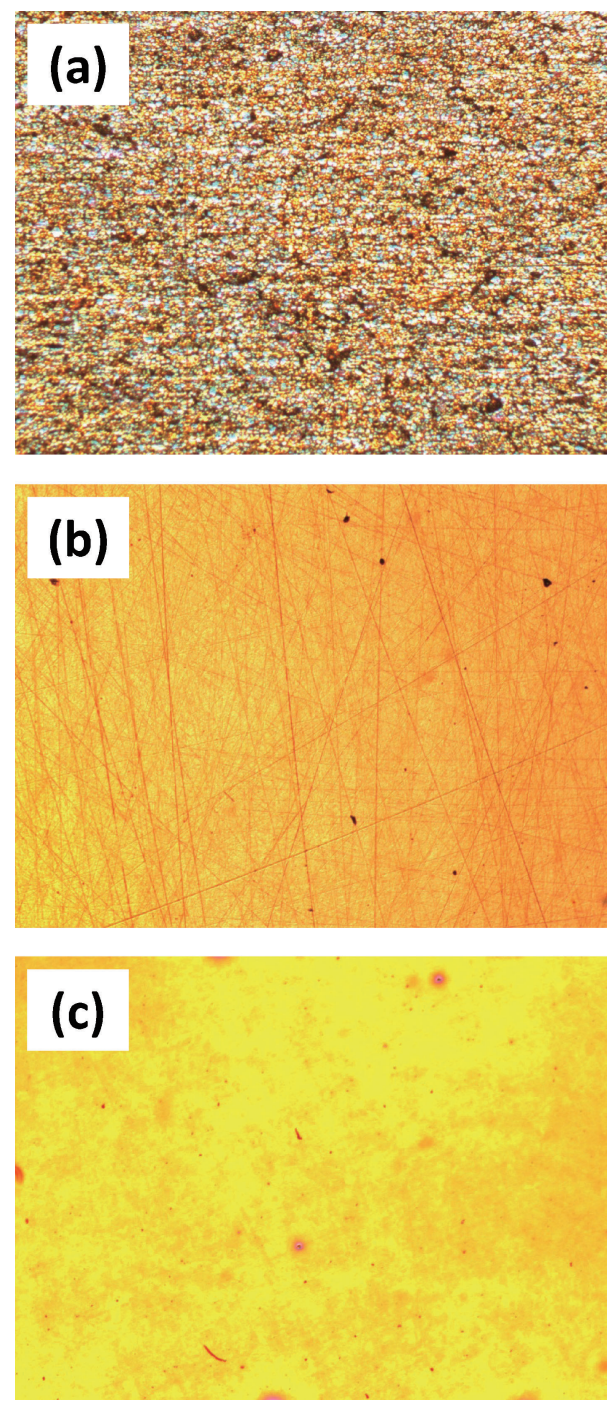

Fig. 6. Optical micrographs of the coated samples: (a) original $(\mathrm{Ra}=$ $0.153 \mu \mathrm{m})$; (b) type A $(\mathrm{Ra}=0.083 \mu \mathrm{m})$; and (c) polished $(\mathrm{Ra}=0.004$ $\mu \mathrm{m})$.

to reduce the stress in the coating. This indicates the importance of realizing a correct phase of drying that minimizes the content of organic residues in the coating.

The appearance of cracks in the coating largely restricts the maximum coating thickness. In this regard, it has been observed that the coatings do not exhibit cracking below a certain critical thickness ranging from 0.5 to $1 \mu \mathrm{m}^{53)}$

The analysis of the cracking evolution of the deposited films (see Fig. 7) shows that not only the amount of deposited ceramic (see Fig. 5) but also the cracking increase with the withdrawal speed of the dip-coating process. Such a behaviour may be attributed to the amount of deposited ceramic, which is directly related to the withdrawal rate (i.e. the higher the speed, the greater the amount deposited on the substrate), and to the increase in the ROH and $\mathrm{H}_{2} \mathrm{O}$ removal during the sintering when the deposition grows.

As an illustrative example, Fig. 8 depicts the SEM micrograph for the ceramic coating deposited on a polished specimen at a withdrawal rate of $50 \mathrm{~mm} \cdot \mathrm{min}^{-1}$. The coating thicknesses for the polished specimens at different speeds are collected in Table 3 . It is seen that the thicknesses obtained at lower speeds fall in the range previously reported in literature. ${ }^{54)}$ The amount of ceramic material deposited is lower with decreasing speed, being the sup- 

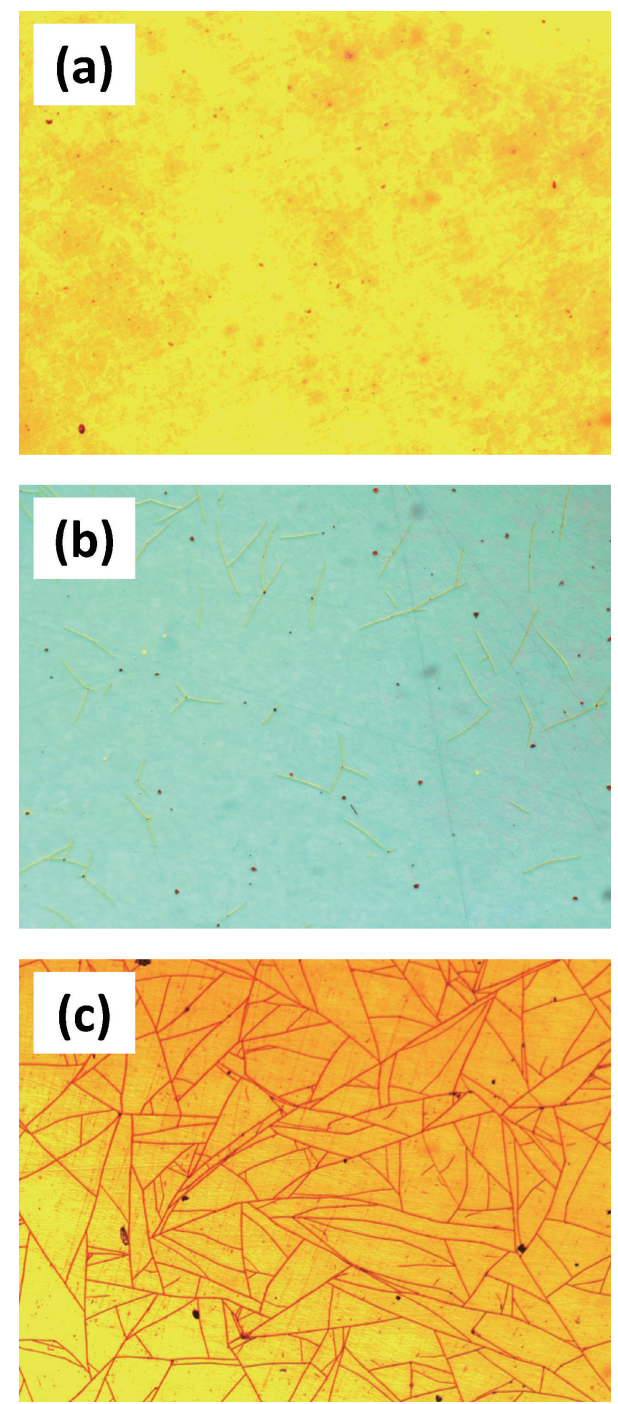

Fig. 7. Optical micrographs of the evolution of the films cracking on the polished substrate for different withdrawal rates: (a) $25 \mathrm{~mm} \cdot \mathrm{min}^{-1}$; (b) $50 \mathrm{~mm} \cdot \mathrm{min}^{-1}$; and (c) $135 \mathrm{~mm} \cdot \mathrm{min}^{-1}$.

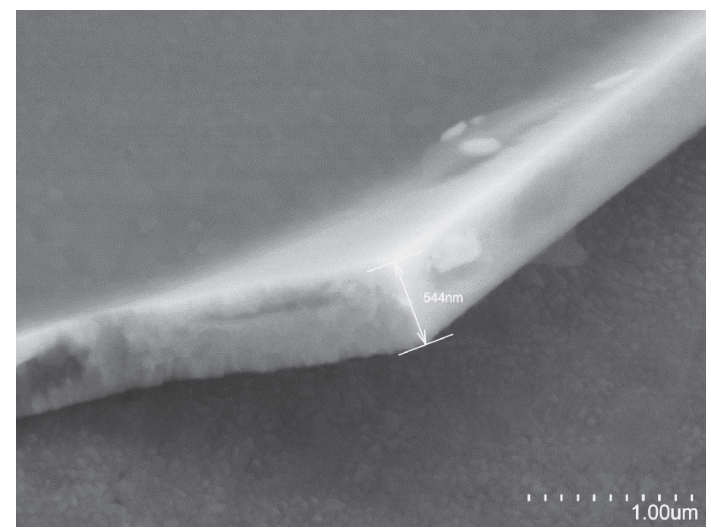

Fig. 8. Coating thickness of polished specimen coated at a withdrawal rate of $50 \mathrm{~mm} \cdot \mathrm{min}^{-1}$.

ported amount quite similar at 25 and $50 \mathrm{~mm} \cdot \mathrm{min}^{-1}$ (448.5 and $544.0 \mathrm{~nm}$ of thickness, respectively), as shown in Fig. 5. This fact suggests that the ceramic amount deposited on the substrate reach a constant value with increasing speed. The study was also
Table 3. Coating thickness

\begin{tabular}{ccc}
\hline Specimen & Withdrawal rate & Coating thickness $(\mathrm{nm})$ \\
\hline \multirow{3}{*}{ Polished } & $25 \mathrm{~mm} \cdot \mathrm{min}^{-1}$ & 448.5 \\
& $50 \mathrm{~mm} \cdot \mathrm{min}^{-1}$ & 544.0 \\
& $135 \mathrm{~mm} \cdot \mathrm{min}^{-1}$ & 1160.0 \\
\hline
\end{tabular}

carried out at lower withdrawal rates, but better results were not obtained, which indicates the existence of an optimal withdrawal rate close to $25 \mathrm{~mm} \cdot \mathrm{min}^{-1}$ or coinciding with this value.

Observing the results above obtained and in concordance with them, it may be affirmed that the coating quality is likely closely related to the low $R_{a}$ value of the polished samples and with the fact that the drained line speed is very close to the withdrawal rate. ${ }^{55)}$

The described electrical characterization was performed in order to analyse the uniformity of the coating's thickness, as described in 2.2.3. For such an aim, the recorded experimental data were treated by suitable software, providing the corresponding coating maps. These plots show the electrical capacitance of the coating measured ( $Z$ axis), which indirectly measure the uniformity of the coating's thickness [Eq. (2.2)], as a function of the coordinates of the points studied on the surface (axes $X$ and $Y$ ). These maps make easy the determination of the uniformity in the coating's thickness, due to the inverse relation between the value of the coating capacitance and its thickness, as described in Eq. (2.2).

The study was carried out by measuring the electrical capacitance at 16 different points widely spread over the coated area of the substrate. To facilitate the study of the uniformity of the coating's thickness, a colour scale for the different intervals of the measured capacitance values was used. Thus, the experimental data are plotted as a function of the substrate roughness at a constant withdrawal rate, leading to the corresponding map. Figure 9 shows the maps registered for the pristine, Type $\mathrm{C}$ and polished substrates coated at $25 \mathrm{~mm} \cdot \mathrm{min}^{-1}$, obtained by measuring the electrical capacitance values on the previously mentioned 16 points. By comparing the above maps, it may be concluded that a greater uniformity in the coating's thickness is obtained after the surface modification, being the discontinuities deeper with higher $\mathrm{Ra}$ values [Original $(\mathrm{Ra}=0.053 \mu \mathrm{m})>$ Type $\mathrm{C}$ $(\mathrm{Ra}=0.027 \mu \mathrm{m})>$ Polished $(\mathrm{Ra}=0.004 \mu \mathrm{m})]$. As can be seen, the coating's thickness is much more uniform across the polished sample [see Fig. 9(c)]. On the other hand, the maps obtained for the substrates coated at three different withdrawal rates and exhibiting a constant $\mathrm{Ra}$ value (polished treatment, $\mathrm{Ra}=0.004$ $\mu \mathrm{m})$ are shown in Fig. 10. As can be seen, the coating's uniformity improves with decreasing speed, as it approaches to an optimum value. Such a behaviour has been attributed to the formation of thinner films at lower withdrawal rates, which involves a lower $\mathrm{ROH}$ and $\mathrm{H}_{2} \mathrm{O}$ release during the sintering and, thereby, a greater uniformity in the coating's thickness. Finally, an area of irregular thickness coating is observed on the edge of all samples. This irregular coating area is likely to be ascribable to edge effects that take place during the coating process, and which are a consequence of possible irregularities during the substrate preparation.

\section{Conclusions}

According to the present work, the previous mechanical treatment of the substrates allows thoroughly modifying their surfaces, making them more homogeneous and improving the 

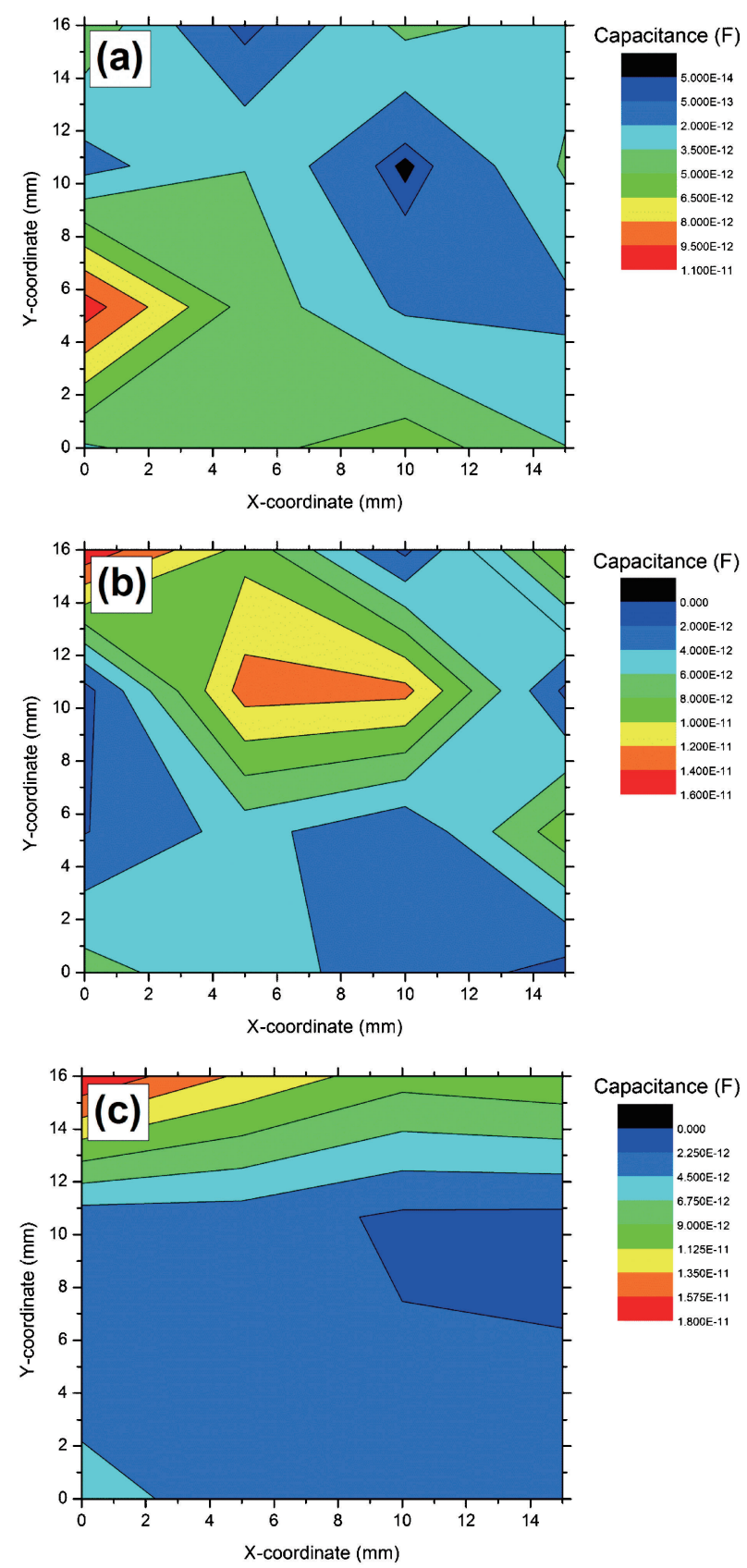

Fig. 9. The coating's uniformity according to the surface modification: (a) original; (b) type C; and (c) polished.

quality of the coatings.

The amount of cracking in the coatings is observed to increase with the withdrawal rate. For the viscosity of the zirconia solution used, the optimum withdrawal rate is $25 \mathrm{~mm} / \mathrm{min}$, or a very close value, and with it the critical coating thickness is obtained.

The coating for the polished specimen is found to be very regular in thickness, which is in good agreement with the Ra parameter. The discontinuities in the coating are deeper with increasing Ra values. Finally, the coating uniformity also improves remarkably when the withdrawal rate approaches to its optimum value.

Finally, a novel electrical method consisting of measuring the electrical capacitance is developed in order to assess the uniformity of the coating's thickness. The results obtained are
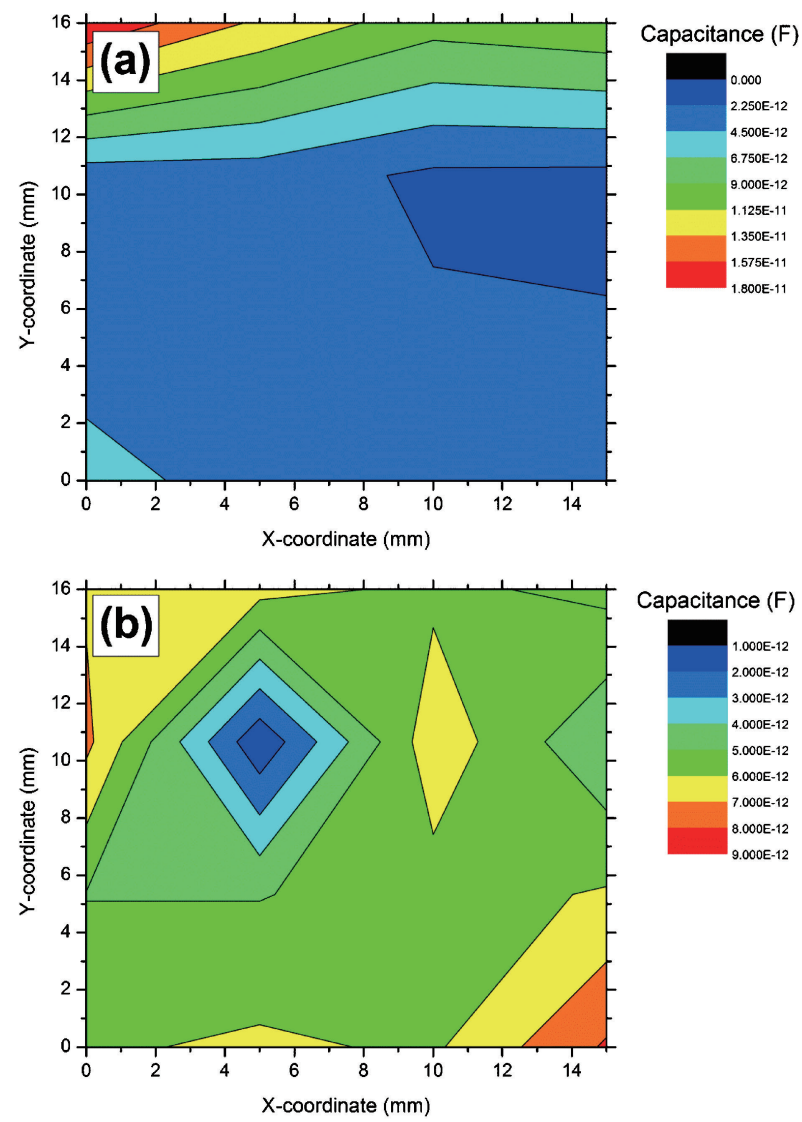

Capacitance (F)

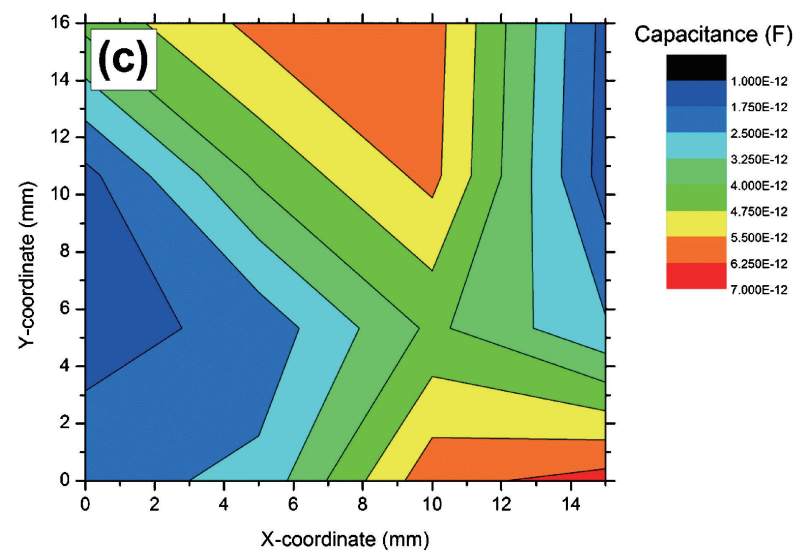

Fig. 10. The coating's uniformity on polished substrates according to the withdrawal rate: (a) $25 \mathrm{~mm} \cdot \mathrm{min}^{-1}$; (b) $50 \mathrm{~mm} \cdot \mathrm{min}^{-1}$; and (c) 135 $\mathrm{mm} \cdot \min ^{-1}$.

well in agreement with those obtained by optical and electron microscopies. The main advantages of this electrical method are the low cost and easy implementation, which render it a feasible support to other well established techniques.

\section{References}

1) M. Wellishetty, P. G. Ranjith and A. Tharumarajah, Resour. Conserv. Recy., 54, 1084-1094 (2010).

2) S. M. Abd El Haleem, S. Abd El Wanees, E. E. Abd El Aal and A. Diab, Corr. Sci., 52, 1675-1686 (2010).

3) H. Choi, Y. K. Song, K. Y. Kim and J. M. Park, Surf. Coat. Tech., 206, 2354-2362 (2012)

4) A. Gergely, I. Bertóti, T. Török, É. Pfeifer and E. Kálmán, Prog. Org. Coat., 76, 17-32 (2013). 
5) M. Finsgar and J. Jackson, Corr. Sci., 86, 17-41 (2014).

6) Z. Liu, Y. Dong, Z. Chu, Y. Yang, Y. Li and D. Yan, Mater. Des., 52, 630-637 (2013).

7) K. Wang, J. Unger, J. D. Torrey, B. D. Flinn and R. K. Bordia, J. Eur. Ceram. Soc., 34, 2597-3606 (2014).

8) X. Shan, L. Q. Wei, P. Liu, X. M. Zhang, W. X. Tang, P. Qian, Y. He and S. F. Ye, Ceram. Int., 40, 12327-12335 (2014).

9) E. Nouri, M. Shahmiri, H. R. Rezaie and F. Talayian, Surf. Coat. Tech., 205, 5109-5115 (2011).

10) M. J. Paterson and B. Ben-Nissan, Surf. Coat. Tech., 86-87, 153-158 (1996).

11) M. Norouzi and A. A. Garekani, Ceram. Int., 40, 2857-2861 (2014).

12) A. Díaz-Parralejo, A. L. Ortiz, R. Caruso and F. Guiberteau, Surf. Coat. Tech., 205, 3540-3545 (2011).

13) J. Mangas-Murillo, E. M. Cuerda-Correa, J. R. Domínguez, A. Macías-García and E. Bernalte, J. Alloys Compd., 577, 360369 (2013).

14) Y. Zhao, L. Lin, X. M. Li and M. K. Lei, NDT Int., 43, 579585 (2010).

15) C. Soo-Haeng, P. Byung-Heong, H. Jin-Mok, L. Han-Soo, S. Kee-Chan and L. Jong-Hyeon, Corr. Sci., 52, 2353-2364 (2010).

16) A. Díaz-Parralejo, A. Macías-García, J. Sánchez-González, M. A. Díaz-Díez and E. M. Cuerda-Correa, Surf. Coat. Tech., 204, 2257-2261 (2010).

17) F. Nanni, F. R. Lamastra, F. Franceschetti, F. Biccari and I. Cacciotti, Ceram. Int., 40, 1851-1858 (2014).

18) X. Wang, G. Wu, B. Zhou and J. Shen, Materials, 6, 76-84 (2013).

19) A. J. Morales-Ramírez, M. García-Hernández, A. GarcíaMurillo, F. J. Carrillo-Romo, J. Moreno-Palmerin, D. Y. Medina-Velazquez and M. L. Carrera-Jota, Materials, 6, 713725 (2013).

20) X. Wang, F. Shi, X. Gao, C. Fan, W. Huang and X. Feng, Thin Solid Films, 548, 34-39 (2013).

21) X. Wang, G. Wu, B. Zhou and J. Shen, Materials, 6, 28192830 (2013).

22) E. Salahinejad, M. J. Hadianfard, D. D. Macdonald, M. Mozafari, D. Vashace and L. Tayebi, Ceram. Int., 39, 12711276 (2013).

23) A. Díaz-Parralejo, A. L. Ortiz and R. Caruso, Ceram. Int., 36, 2281-2286 (2010).

24) S. Chaki, P. Marical, S. Panier, G. Bourse and A. Mouftiez, NDT Int., 44, 519-522 (2011).

25) R. Molina, Y. Segura, F. Martínez and J. A. Melero, Chem Eng. J., 203, 212-222 (2012).

26) E. Nouri, M. Shahmiri, H. R. Rezaie and F. Talayian, Surf. Coat. Tech., 205, 5109-5115 (2011).

27) J. Y. Han, Z. T. Yu and L. Zhou, Appl. Surf. Sci., 255, 455-458 (2008).

28) F. Malekmohammadi, A. S. Rouhaghdam and T. Shahrabi, J. Non-Cryst. Solids, 357, 1141-1146 (2011).

29) Y. Adraider, Y. X. Pang, F. Nabhani, S. N. Hodgson, M. C. Sharp and A. Al-Waidh, Ceram. Int., 39, 9665-9670 (2013).

30) H. Li, K. Liang, L. Mei, S. Gu and S. Wang, Mater. Lett., 51,
320-324 (2001).

31) S. K. Tiwari, J. Adhikary, T. B. Singh and R. Singh, Thin Solid Films, 517, 4502-4508 (2009).

32) L. F. Deng, Y. S. Xiong and P. Xiao, Surf. Coat. Tech., 201, 7755-7763 (2007).

33) X. Wang, J. Mei and P. Xiao, J. Eur. Ceram. Soc., 21, 855-865 (2001).

34) J. Cheng-Chung, C. Ming-Hwu, C. Jyh-Shin, T. Chuen-Horng, Y. Py-Shiun, K. Jiann-Shiun and H. Ho-Yen, Appl. Surf. Sci., 169-170, 649-653 (2001).

35) S. Roncallo, J. D. Painter, M. A. Cousins, D. W. Lane and K. D. Rogers, Thin Solid Films, 516, 8493-8497 (2008).

36) M. C. Salvadori, D. R. Martins and M. Cattani, Surf. Coat. Tech., 200, 5119-5122 (2006).

37) Y. Liu, Y. Zou, L. Zhao, W. Liu and L. Cheng, Int. Commun. Heat Mass, 38, 730-733 (2011).

38) B. Arifvianto, M. Mahardika, P. Dewo, P. T. Iswanto and U. A. Salim, Materials Chemistry and Physics, 125, 418-426 (2011).

39) A. Díaz-Parralejo, A. Macías-García, J. Sánchez-González, M. A. Díaz-Díez and E. M. Cuerda-Correa, J. Non-Cryst. Solids, 357, 1090-1095 (2011).

40) W. M. Haynes, "CRC Handbook of Chemistry and Physics", 95th Edition, Hardcover (2014).

41) I. G. Tredici, F. Maglia, A. Resmini and U. AnselmiTamburini, Thin Solid Films, 542, 52-59 (2013).

42) L. Xu, S. Xiao, C. Zhang, G. Zheng, J. Su, L. Zhao and J. Wang, Mater. Chem. Phys., 148, 720-726 (2014).

$43)$ S. Roncallo, J. D. Painter, S. A. Ritchie, M. A. Cousins, M. V. Finnis and K. D. Rogers, Thin Solid Films, 518, 4821-4827 (2010).

44) C. Youn-Ok, K. Nam-Hoon, P. Ju-Sun and L. Woo-Sun, Mater Sci. Eng., B, 171, 73-78 (2010).

45) C. Li, Y. Wang and D. C. Ba, Physics Procedia, 32, 347-355 (2012).

46) J. Zhicheng, L. Yiwei, W.-F. Chung, C.-Y. Cheung, I. Yagi and T. Hong, Sci. China, 44, 393-399 (2001).

47) A. Koltsov, M.-J. Cornu and D. Loison, Surf. Coat. Tech., 206, 2759-2768 (2012).

48) M. J. Paterson and B. Ben-Nissan, Surf. Coat. Tech., 86-87, 153-158 (1996).

49) A. Balamurugan, G. Balossier, S. Kannan, J. Michel, J. Faure and S. Rajeswari, Ceram. Int., 33, 605-614 (2007).

50) Y. Adraider, Y. X. Pang, F. Nabhani, S. N. Hodgson, M. C. Sharp and A. Al-Waidh, Ceram. Int., 40, 6151-6156 (2014).

51) D. A. Gómez-Hernández, P. A. Jurado-Ortiz, A. RubenMuñoz, J. De la Roche-Yepes, J. M. González and O. Sequeda, Informador Técnico, 74, 39-43 (2010).

52) G. P. Singh, J. Alphonsa, P. K. Barhai, P. A. Rayjada, P. M. Raole and S. Mukherjee, Surf. Coat. Tech., 200, 5807-5811 (2006).

53) S. G. Croll, J. Appl. Polym. Sci., 23, 847-858 (1979)

54) C. J. Brinker and G. W. Scherer, "Sol-Gel Science: The Physics and Chemistry of Sol-Gel Processing", Chapter 14, Academic Press, New York (1990).

55) C. J. Brinker, G. C. Frye, A. J. Hurd and C. S. Ashley, Thin Solid Films, 201, 97-108 (1991). 